\title{
Preparation of Soluble Poly(azomethine)s Having the $\beta$-Diketonate Metal Complex in the Main Chain
}

\author{
Kensuke NAKA, ${ }^{\dagger}$ Etsuo HorII, and Yoshiki $\mathrm{CHUJO}^{\dagger}$ \\ Department of Polymer Chemistry, Graduate School of Engineering, Kyoto University, \\ Yoshida, Sakyo-ku, Kyoto 606-8501, Japan
}

(Received March 29, 1999)

\begin{abstract}
Copper complexes (2a-Cu and 2b-Cu) having two amino groups were prepared from $p$ aminobenzoylacetone (1a) and 1-(4-aminophenyl)nonane-1,3-dione (1b) with copper(II) acetate, respectively. A soluble poly(azomethine) having $\beta$-diketonato copper(II) complex in the main chain was prepared by the polycondensation of 2b-Cu with terephthalaldehyde (3) in dimethyl sulfoxide (DMSO) at room temperature with $\mathrm{H}_{2} \mathrm{SO}_{4}$ as catalyst. After reprecipitation into methanol, a green product was obtained in $56 \%$ yield. The complex (5b-Cu) was soluble in common organic solvents such as $\mathrm{CHCl}_{3}$, tetrahydrofuran (THF), and DMSO. The number-average molecular weight $\left(M_{n}\right)$ and molecular weight distribution of $\mathbf{5 b}-\mathbf{C u}$ determined by GPC were $M_{n}=3500$ (polystyrene standard) and $M_{w} / M_{n}=1.71$, respectively. The structure of $\mathbf{5 b}-\mathbf{C u}$ was supported by IR and elemental analysis. Thermogravimetric analysis (TGA) for 5b-Cu showed $5 \%$ weight loss at $250^{\circ} \mathrm{C}$ under nitrogen. Electrochemical data as well as absorption spectra of $\mathbf{5 b}-\mathbf{C u}$ in comparison with that of copper(II) bis[p-(1-aza-2-phenylethenyl)benzoylacetonate] (6) as a model compound show that the metal centers of the multinuclear complexes may be considered nearly independent of one another.

KEY WORDS Poly(azomethine) / $\beta$-Diketonate Copper(II) Complex / Coordination Polymer / Metal-

Containing Polymer / Cyclic Voltammetry /
\end{abstract}

Poly(azomethine)s are readily prepared by reactions of a diamine with a dialdehyde. ${ }^{1,2}$ Interest has been focused on poly(azomethine)s because of their thermal stability, electrical conduction, and photoconduction. Several conjugated poly(azomethine)s have been prepared and used to investigate the effects of molecular structure on the electronic and optical properties. ${ }^{3-8}$ This paper describes the synthesis of a soluble poly(azomethine) having $\beta$-diketonate copper(II) complex in the main chain. The polymerization was carried out through chemical coupling of an aromatic dialdehyde and diamine monomer of a metal complex. Our synthetic method provides a well-defined metal containing $\pi$ conjugated poly(azomethine) in which a $\pi$-conjugated spacer is directly attached to the metal coordination center. Soluble conjugated azomethine polymers having $\beta$ diketonate complex units in the main chain have been unknown prior to this study.

Metal-containing polymeric materials are interesting for their useful redox, magnetic, optical, electrical, and catalytic properties. ${ }^{10,11}$ In the past, several attempts have been made to prepare coordination polymers containing $\beta$-diketonate. ${ }^{12-14}$ However, the solubility of most products in common organic solvents was low. Examples of soluble linear coordination polymers with transition metal ions in the main chain are limited. These problems arise from the inherent skeletal rigidity of these materials, and the introduction of solubilizing or flexiblizing groups either in the polymer backbone or side group structure is necessary for useful products to be obtained. The condensation of the substitution-inert bis( $\beta$-diketone) complexes of cobalt(III) and chromium(III) with sulfur halides provides soluble metal coordination polymers. ${ }^{12}$ Several metal ions such as nickel(II), copper(II), zinc(II) could not produce coordination poly-

\footnotetext{
${ }^{\dagger}$ To whom correspondence should be addressed.
}

mers by these methods. ${ }^{15}$

\section{EXPERIMENTAL}

\section{Measurements}

${ }^{1} \mathrm{H}$ NMR and IR spectra were recorded on a JEOL JNM-EX270 spectrometer and Perkin Elmer 1600 spectrometer, respectively. TGA was made on a Shimadzu DT-30 instrument $\left(10^{\circ} \mathrm{C} \mathrm{min}{ }^{-1}\right)$. UV spectra were made on a JASCO V-530 spectrophotometer. Cyclic voltammetry was carried out with a BAS CV-50W electrochemical analyzer. Gel permeation chromatography was carried out on a Tosoh $\mathrm{G}_{3000 \mathrm{H}_{\mathrm{XL}}}$ using tetrahydrofuran (THF) as eluent after calibration with standard polystyrene samples. DSC analysis was carried out on a Seiko DSC 200 instrument using $6 \mathrm{mg}$ exactly weighed sample. Fast atom bombardment spectra (FAB-MS) were obtained on a JEOL JMS-SX102A using $m$-nitrobenzyl alcohol as a matrix.

\section{Materials}

Unless stated otherwise, all reagents and chemicals were obtained from commercial sources and used without further purification. Chloroform, toluene, and dimethyl sulfoxide (DMSO) were distilled under nitrogen over $\mathrm{P}_{2} \mathrm{O}_{5}$. $p$-Aminobenzoylacetone (1a) was prepared by reduction of $p$-nitrobenzoylacetone by $\mathrm{Pd}-\mathrm{C}$ in methanol according to the literature. ${ }^{16}$

\section{1-(4-Nitrophenyl)nonane-1,3-dione}

To a mixture of $p$-nitroacetophenone $(5.00 \mathrm{~g}, 30.3$ mmol) and heptanoic anhydride $(22 \mathrm{~mL}, 83.8 \mathrm{mmol})$ was added boron trifluoride-acetic acid complex $(15 \mathrm{~mL})$ at room temperature. The solution was stirred at room temperature for $44 \mathrm{~h}$. The reaction mixture was then added to $80 \mathrm{~mL} 13 \%$ sodium acetate solution, and the resulting mixture was heated under reflux for $3 \mathrm{~h}$. The 
mixture was cooled and the organic phase was separated. The aqueous phase was extracted with ethyl acetate (AcOEt), and the combined organic phase was dried over anhydrous $\mathrm{Na}_{2} \mathrm{SO}_{4}$. Removal of the solvent under reduced pressure afforded an oily product, which was purified by column chromatography (silica ; hexane/ AcOEt $\left.=2 / 1, \mathrm{v} / \mathrm{v}, \mathrm{R}_{\mathrm{f}}=0.58\right)$ to give $5.94 \mathrm{~g}(21.4 \mathrm{mmol}$, yield $71 \%)$ of a pure product as an oil. ${ }^{1} \mathrm{H} \mathrm{NMR}\left(\mathrm{CDCl}_{3}\right) \delta$ $0.88\left(3 \mathrm{H}, \mathrm{t}, \mathrm{J}=4.3 \mathrm{~Hz}, \mathrm{CH}_{3}\right), 1.29\left(6 \mathrm{H}, \mathrm{m}, \mathrm{CH}_{2}\right), 1.70(2$ $\left.\mathrm{H}, \mathrm{m}, \mathrm{COCH}_{2}-\mathrm{CH}_{2}\right), 2.48\left(2 \mathrm{H}, \mathrm{t}, J=8.1 \mathrm{~Hz}, \mathrm{COCH}_{2}\right)$, $6.22(1 \mathrm{H}, \mathrm{s}, \mathrm{C}(\mathrm{OH})=C H-\mathrm{CO}), 8.03(2 \mathrm{H}, \mathrm{d}, J=8.9 \mathrm{~Hz}, \mathrm{Ar}-$ $H$ ), $8.29(2 \mathrm{H}, \mathrm{d}, J=8.9 \mathrm{~Hz}, \mathrm{Ar}-H)$.

\section{1-(4-Aminophenyl)nonane-1,3-dione (1b)}

First, $5 \%$ Pd-C (0.5 g) was put into a two-necked flask under argon and then ethanol was poured into the flask. After bubbling the solution with argon gas for $1 \mathrm{~h}, 1$-(4nitrophenyl)nonane-1,3-dione was added to the solution. Hydrogen gas was substituted for argon gas and the solution was stirred for 2 days. After the reaction was finished, Pd-C was removed by filtration. Removal of the solvent under reduced pressure afforded a red oily product (crude yield 100\%). ${ }^{1} \mathrm{H} \mathrm{NMR}\left(\mathrm{CDCl}_{3}\right): \delta 0.89(3 \mathrm{H}, \mathrm{m}$, $\left.\mathrm{CH}_{3}\right), 1.32\left(6 \mathrm{H}, \mathrm{m}, \mathrm{CH}_{2}\right), 1.68\left(2 \mathrm{H}, \mathrm{m}, \mathrm{COCH}_{2}-\mathrm{CH}_{2}\right), 2.36$ $\left(2 \mathrm{H}, \mathrm{t}, J=7.6 \mathrm{~Hz}, \mathrm{COCH} \mathrm{H}_{2}\right), 4.06\left(2 \mathrm{H}, \mathrm{br}, \mathrm{NH}_{2}\right), 6.05(1 \mathrm{H}$, $\mathrm{s}, \mathrm{C}(\mathrm{OH})=C H-\mathrm{CO}), 6.67(2 \mathrm{H}, \mathrm{d}, J=8.6 \mathrm{~Hz}, \mathrm{Ar}-H), 7.75$ $(2 \mathrm{H}, \mathrm{d}, J=8.6 \mathrm{~Hz}, \mathrm{Ar}-H)$.

\section{$\beta$-Diketonate Complexes}

A typical procedure is as follows. To a prerefluxed solution of $p$-aminobenzoyl-acetone $(1.78 \mathrm{~g}, 10.0 \mathrm{mmol})$ in methanol $(100 \mathrm{~mL})$ were added a solution of $\mathrm{Cu}(\mathrm{OAc})_{2}$. $\mathrm{H}_{2} \mathrm{O}(0.998 \mathrm{~g}, 5.0 \mathrm{mmol})$ and $16 \mathrm{~N} \mathrm{NH}_{3} \mathrm{aq}(1 \mathrm{~mL})$ in water under nitrogen. A green compound immediately precipitated. The reaction mixture was stirred under reflux condition for $3 \mathrm{~h}$. The precipitate was filtered and washed with water $(1 \times 20 \mathrm{~mL})$ and cold methanol $(2 \times 10$ $\mathrm{mL})$. The product was further purified by recrystallization from 2-ethoxyethanol to give $1.47 \mathrm{~g}(3.53 \mathrm{mmol}$, yield $71 \%$ ) of copper(II) bis( $p$-aminobenzoylacetonate) (2a-Cu). IR ( KBr, cm $\left.{ }^{-1}\right) 3368\left(\mathrm{NH}_{2}\right), 1626(\mathrm{C}=\mathrm{C}), 1529$ $(\mathrm{C}=\mathrm{O}), 1496(\mathrm{C}=\mathrm{O})$. FAB-MS : $m / z 416\left(\mathrm{M}^{+}\right), \mathrm{C}_{20} \mathrm{H}_{20} \mathrm{~N}_{2^{-}}$ $\mathrm{O}_{4} \mathrm{Cu}$ required $\mathrm{M}^{+}=416$. Anal. Calcd for $\mathrm{C}_{20} \mathrm{H}_{20} \mathrm{~N}_{2} \mathrm{O}_{4^{-}}$ $\mathrm{Cu}$ : H 4.85 ; C 57.75; N 6.73. Found: H 5.00 ; C 57.97 ; N 6.90 .

2b-Cu (yield $41 \%)$. IR ( $\left.\mathrm{KBr}, \mathrm{cm}^{-1}\right), 3401\left(\mathrm{NH}_{2}\right), 1635$ $(\mathrm{C}=\mathrm{C}), 1529(\mathrm{C}=\mathrm{O}), 1500(\mathrm{C}=\mathrm{O})$. FAB-MS : $\mathrm{m} / \mathrm{z} 556$ $\left(\mathrm{M}^{+}\right), \mathrm{C}_{30} \mathrm{H}_{40} \mathrm{~N}_{2} \mathrm{O}_{4} \mathrm{Cu}$ required $\mathrm{M}^{+}=556$. Anal. Calcd for $\mathrm{C}_{30} \mathrm{H}_{40} \mathrm{~N}_{2} \mathrm{O}_{4} \mathrm{Cu}: \mathrm{H} 7.25$; C 64.80; N 5.04. Found : $\mathrm{H}$ 7.42 ; C 64.93 ; N 5.33.

2a-Ni (yield 74\%). IR $\left(\mathrm{KBr}, \mathrm{cm}^{-1}\right) 3316\left(\mathrm{NH}_{2}\right) 1588(\mathrm{C}$ $=\mathrm{C}), 1524(\mathrm{C}=\mathrm{O}), 1501(\mathrm{C}=\mathrm{O})$. Anal. Calcd for $\mathrm{C}_{20} \mathrm{H}_{20^{-}}$ $\mathrm{N}_{2} \mathrm{O}_{4} \mathrm{Ni} \cdot 1.0 \mathrm{H}_{2} \mathrm{O}: \mathrm{H} 4.93 ; \mathrm{C} 55.99 ; \mathrm{N} 6.50$. Found : $\mathrm{H}$ 5.11 ; C 56.39 ; N 6.58.

2b-Ni (yield 51\%). IR (KBr, cm ${ }^{-1}$ ) $3359(\mathrm{NH} \mathrm{2),} 1595$ $(\mathrm{C}=\mathrm{C}), 1525(\mathrm{C}=\mathrm{O}), 1504(\mathrm{C}=\mathrm{O})$. FAB-MS : $m / z 551$ $\left(\mathrm{M}^{+}\right), \mathrm{C}_{30} \mathrm{H}_{40} \mathrm{~N}_{2} \mathrm{O}_{4} \mathrm{Ni}$ required $\mathrm{M}^{+}=551$. Anal. Calcd for $\mathrm{C}_{30} \mathrm{H}_{40} \mathrm{~N}_{2} \mathrm{O}_{4} \mathrm{Ni} \cdot 3.3 \mathrm{H}_{2} \mathrm{O}: \mathrm{H} 7.68 ; \mathrm{C} 58.89 ; \mathrm{N} 4.23$. Found : H 7.24 ; C 58.33 ; N 4.65 .

\section{Triethylene Glycol Bis(p-formylphenyl) Ether (4)}

To a prerefluxed suspension of $\mathrm{K}_{2} \mathrm{CO}_{3}(1.87 \mathrm{~g}, 13.5$ $\mathrm{mmol})$ in THF $(30 \mathrm{~mL})$ were added a solution of $p$ -

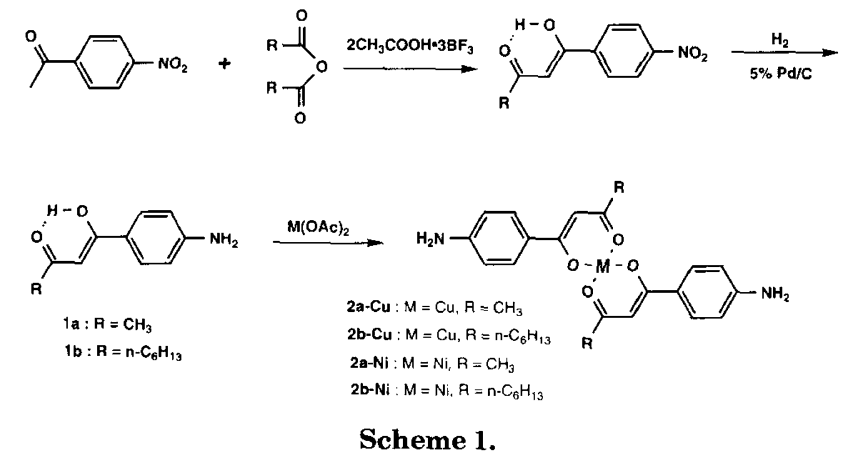

hydroxybenzaldehyde $(1.84 \mathrm{~g}, 15.1 \mathrm{mmol})$ and triethylene glycol di-p-toluenesulfonate $(2.30 \mathrm{~g}, 5.01 \mathrm{mmol})$ in THF (30 mL) under nitrogen. The mixture was stirred under reflux condition for 4 days. The product mixture was concentrated under reduced pressure, diluted with $100 \mathrm{~mL}$ of AcOEt, and washed with water $(50 \mathrm{~mL})$. The aqueous phase was extracted with AcOEt $(1 \times 20 \mathrm{~mL})$ and the combined organic phase was dried over anhydrous $\mathrm{Na}_{2} \mathrm{SO}_{4}$. Removal of the solvent under reduced pressure afforded a residue, which was purified by column chromatography (silica ; hexane/AcOEt =1/1, v/v) to give $1.53 \mathrm{~g}(4.27 \mathrm{mmol}$, yield $86 \%)$ of a pure product as a white solid. ${ }^{1} \mathrm{H}$ NMR $\left(\mathrm{CDCl}_{3}\right): \delta 3.77\left(4 \mathrm{H}, \mathrm{s}, \mathrm{O}-\mathrm{CH}_{2}\right)$, $3.90\left(4 \mathrm{H}, \mathrm{t}, J=4.9 \mathrm{~Hz}, \mathrm{PhOCH}_{2}-\mathrm{CH}_{2}\right), 4.21(4 \mathrm{H}, \mathrm{t}, J=$ $\left.4.9 \mathrm{~Hz}, \mathrm{PhO}-\mathrm{CH}_{2}\right), 7.01(4 \mathrm{H}, \mathrm{d}, J=8.9 \mathrm{~Hz}, \mathrm{Ar}-\mathrm{H}), 7.82(4$ $\mathrm{H}, \mathrm{d}, J=8.9 \mathrm{~Hz}, \mathrm{Ar}-H), 9.88(2 \mathrm{H}, \mathrm{s}, \mathrm{CHO})$.

\section{Copper(II) Bis[p-(1-aza-2-phenylethenyl)benzoylaceto- nate] (6)}

To a solution of copper(II) bis( $p$-aminobenzoylacetonate) (2a-Cu) $(0.5 \mathrm{~g}, 1.20 \mathrm{mmol})$ in DMSO $(5 \mathrm{~mL})$ was added one drop of conc. sulfuric acid under nitrogen. The reaction mixture was stirred at room temperature for 1 day. The product mixture was poured into methanol $(100 \mathrm{~mL})$ and the product precipitate was filtered and washed with water and methanol to give $0.554 \mathrm{~g}(0.936$ mmol, yield $78 \%$ ) of the compound 6. IR $\left(\mathrm{KBr}, \mathrm{cm}^{-1}\right)$ : $1635(\mathrm{C}=\mathrm{C}), 1579(\mathrm{C}=\mathrm{N}), 1519(\mathrm{C}=\mathrm{O}), 1490(\mathrm{C}=\mathrm{O})$. Anal. Calcd for $\mathrm{C}_{34} \mathrm{H}_{28} \mathrm{O}_{4} \mathrm{~N}_{2} \mathrm{Cu}$ : $\mathrm{H} 4.77 ; \mathrm{C} 68.96 ; \mathrm{N}$ 4.73. Found : H 4.67 ; C 68.31 ; N 4.66.

\section{Polymerization}

A typical procedure is as follows. An example of run 1 in Table $\mathrm{I}$ is shown. To a solution of $\beta$-diketonate complex 2b-Cu $(0.111 \mathrm{~g}, 0.20 \mathrm{mmol})$ and terephthalaledehyde (3) $(0.027 \mathrm{~g}, 0.20 \mathrm{mmol})$ in DMSO $(5 \mathrm{~mL})$ was added one drop of conc. sulfuric acid under nitrogen. The reaction mixture was stirred at room temperature for 4 days. The product mixture was poured into water $(100 \mathrm{~mL})$ and the product precipitate was filtered. Reprecipitation of chloroform solution of the crude product into hexane gave $73.5 \mathrm{mg}$ (yield $56 \%$ ) of a polymer product as a green solid. IR $\left(\mathrm{KBr}, \mathrm{cm}^{-1}\right) 1699(\mathrm{CHO}), 1595(\mathrm{C}=\mathrm{N}), 1519(\mathrm{C}$ $=\mathrm{O}), 1503(\mathrm{C}=\mathrm{O})$. Anal. Calcd for $\left(\mathrm{C}_{38} \mathrm{H}_{42} \mathrm{O}_{4} \mathrm{~N}_{2} \mathrm{Cu}\right)_{n}: \mathrm{H}$ 6.47 ; C 69.76 ; N 4.28. Found : H 6.92 ; C 69.16 ; N 4.36 . 


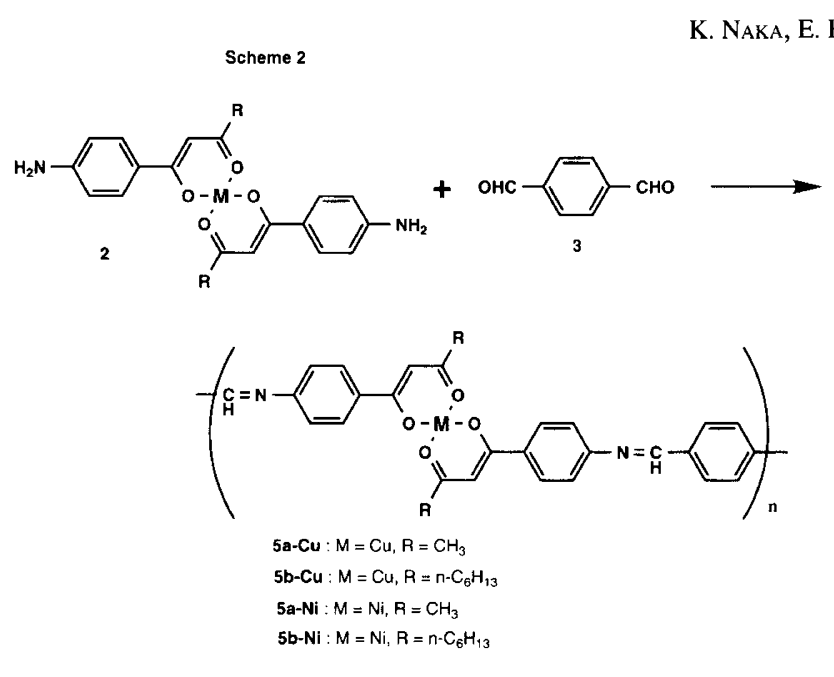

Scheme 2.

\section{RESULTS AND DISCUSSION}

\section{Monomer Synthesis}

An amine-substituted $\beta$-diketone, i.e., $p$-aminobenzoylacetone (1a) was prepared according to the literature by the acylation of ketone with $\mathrm{BF}_{3} \cdot{ }^{17}$ To improve the solubility of the product during polymerization, 1-(4aminophenyl)nonane-1,3-dione (1) $)$ was also prepared. Copper complexes (2a-Cu and $\mathbf{2 b}-\mathbf{C u}$ ) having two amino groups, in which the metal replaces the enolic hydrogen and a six-membered chelate ring is produced, were easily obtained by a reaction of the $\beta$-diketone and copper (II) acetate in methanol. The metal complexes were obtained as green solids. The structures of the complexes were supported by IR, FAB-MASS, and elemental analysis. The IR spectrum of 1 a showed strong peaks at 1723 $\mathrm{cm}^{-1}$ and $1637 \mathrm{~cm}^{-1}$ due to a $\mathrm{C}=\mathrm{O}$ stretching vibration of the keto-form and a $\mathrm{C}=\mathrm{O}$ stretching vibration of the enol-form, respectively. ${ }^{18}$ The copper complex (2a-Cu) showed strong peaks at 1529 and $1496 \mathrm{~cm}^{-1}$ which were assigned to a metal coordinated $\mathrm{C}=\mathrm{O}$ vibration. ${ }^{18,19}$ The peaks due to the $\mathrm{C}=\mathrm{O}$ stretching vibration for the ketoand the enol-forms of 1a disappeared. The IR spectrum of $\mathbf{2 b - C u}$ also supported the complex formation. The trans isomer might be the main product estimated by thin layer chromatography. ${ }^{20}$ Nickel complexes (2a-Ni and $\mathbf{2 b}-\mathrm{Ni}$ ) having two amino groups were also prepared by the reaction of 1 with nickel(II) acetate in methanol.

The monomer 2a-Cu was soluble in DMSO and $N, N$ dimethylformamide (DMF), whereas $\mathbf{2 a - N i}$ was only soluble in hot DMSO and hot DMF. Less solubility of the nickel complex compared with the copper complex was due to a tetrahedral configuration of nickel(II) acetylacetonato unit. On the other hand, copper(II) acetylacetonato moiety is a square-planer configuration, in which electron donating solvents can interact with the central metal ions. ${ }^{19}$ The remarkable solubility of copper(II) $\beta$ diketonates in solution is due to donor-acceptor interactions with solvent molecules. The complexes derived from the ligand having 1,3-octanedione unit (2b-Cu and 2b-Ni) were soluble in common organic solvents such as $\mathrm{CHCl}_{3}, \mathrm{THF}$, and toluene, as well as in DMSO and DMF.

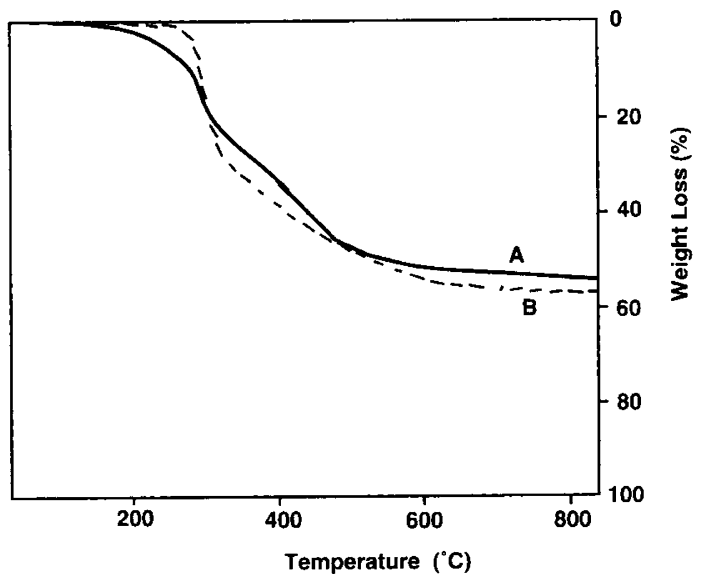

Figure 1. TGA trace of 5 b-Cu (A) and 6 (B) under nitrogen.

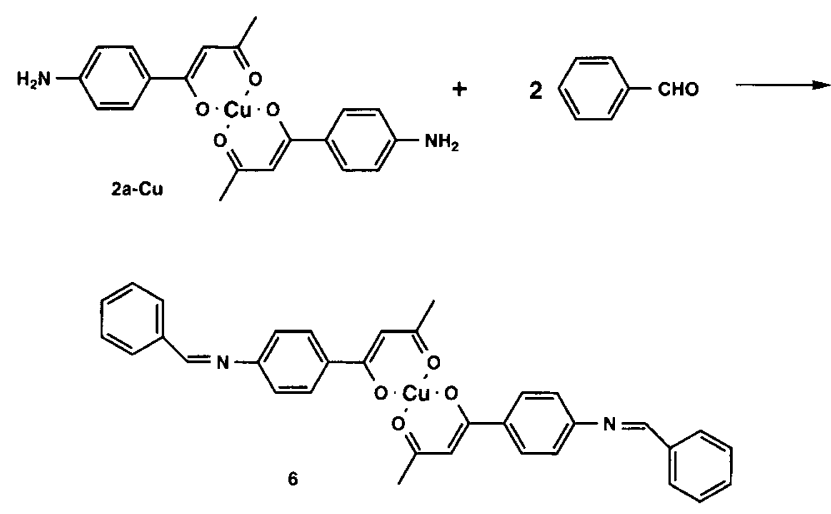

Scheme 3.

\section{Polymerization}

Polymerization of $\mathbf{2 a - C u}$ with terephthalaldehyde (3) was carried out in DMSO at room temperature with $\mathrm{H}_{2} \mathrm{SO}_{4}$ as a catalyst (Scheme 2). The product was immediately precipitated. After the precipitate was filtered and washed with methanol, a dark green product was obtained in $53 \%$ yield. The obtained product was insoluble in common organic solvents. The IR spectrum of the product shows strong peak at $1580 \mathrm{~cm}^{-1}$ due to $\mathrm{C}=\mathrm{N}$ vibration. A weak peak at $1698 \mathrm{~cm}^{-1}$ due to the terminal aldehyde group also appeared. Reaction of $\mathbf{2 a - N i}$ with $\mathbf{3}$ in DMSO at $60^{\circ} \mathrm{C}$ with $\mathrm{H}_{2} \mathrm{SO}_{4}$ as a catalyst gave an insoluble product in $74 \%$ yield. The polymerization of $\mathbf{2 a - C u}$ with a flexible dialdehyde, i.e., triethylene glycol bis $(p-$ formylphenyl) ether (4), was performed in DMSO at room temperature with $\mathrm{H}_{2} \mathrm{SO}_{4}$ for $48 \mathrm{~h}$. The product was precipitated during polymerization. The resulting product was partially soluble in DMSO and DMF.

The polycondensation of $\mathbf{2 b - C u}$ with $\mathbf{3}$ was carried out in DMSO at room temperature with $\mathrm{H}_{2} \mathrm{SO}_{4}$ as a catalyst (Scheme 2). Polymerization was performed in a homogeneous solution. After reprecipitation into methanol, a green product was obtained in $56 \%$ yield. The obtained complex was soluble in common organic solvents such as $\mathrm{CHCl}_{3}$, THF, and DMSO. The number-average molecular weight $\left(M_{n}\right)$ and molecular weight distribution of the complex determined by GPC were $M_{n}=3500$ (polystyrene standard) and $M_{w} / M_{n}=1.71$, respectively.

The structure of the oligomer $\mathbf{5 b} \mathbf{b}-\mathbf{C u}$ was supported by 
Table I. Polymerization of $\mathbf{2 b}-\mathbf{C u}$ with dialdehyde

\begin{tabular}{|c|c|c|c|c|c|c|c|c|}
\hline Run & Dialdehyde & Solvent & Additive & Temp & Time/h & Yield $/ \%^{a}$ & $M_{n}^{\mathrm{b}}$ & $M_{w} / M_{n}^{\mathrm{b}}$ \\
\hline 1 & 3 & DMSO & $\mathrm{H}_{2} \mathrm{SO}_{4}$ & r.t. & 78 & 56 & 3500 & 1.71 \\
\hline 2 & $\mathbf{3}$ & $\mathrm{CHCl}_{3}$ & $\mathrm{LiCl}^{4}$ & reflux & 100 & 74 & 610 & 1.89 \\
\hline 3 & 3 & Toluene & $\mathrm{LiCl}$ & reflux & 96 & 86 & 2600 & 1.03 \\
\hline 4 & 3 & Toluene & MS4 $\AA$ & reflux & 48 & 21 & 1000 & 1.65 \\
\hline 5 & 4 & DMSO & $\mathrm{H}_{2} \mathrm{SO}_{4}$ & r.t. & 168 & 0 & & \\
\hline 6 & 4 & Toluene & $\mathrm{LiCl}^{4}$ & reflux & 168 & 65 & 1600 & 1.18 \\
\hline
\end{tabular}

${ }^{\mathrm{a}}$ Isolated yields after reprecipitation into $n$-hexane. ${ }^{\mathrm{b}}$ Determined by GPC (THF) and polystyrene standards.

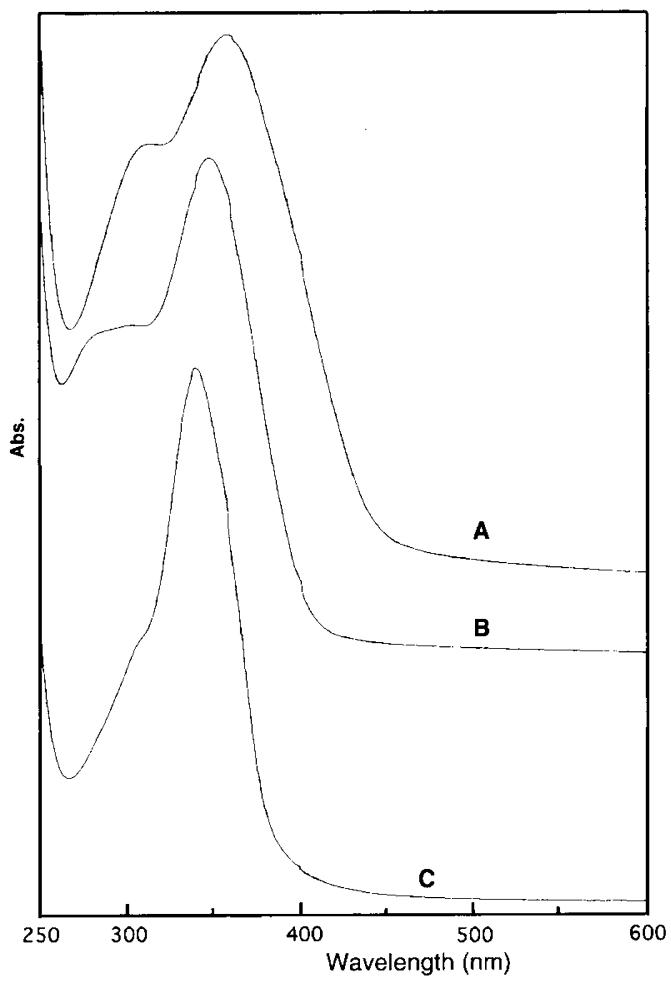

Figure 2. UV-Vis spectra of $5 \mathbf{b}-\mathbf{C u}(\mathrm{A}), \mathbf{6}(\mathrm{B})$, and $\mathbf{2 b - C u}(\mathrm{C})$ in chloroform.

IR and elemental analysis. The IR spectrum of $\mathbf{5 b}-\mathbf{C u}$ showed a strong peak at $1595 \mathrm{~cm}^{-1}$ due to a $\mathrm{C}=\mathrm{N}$ vibration and strong peaks at 1519 and $1503 \mathrm{~cm}^{-1}$ which were assigned to metal coordinated $\mathrm{C}=\mathrm{O}$ vibration. A weak peak at $1699 \mathrm{~cm}^{-1}$ due to the terminal aldehyde group also appeared. The IR spectrum showed no peak at $1723 \mathrm{~cm}^{-1}$ due to $\mathrm{C}=\mathrm{O}$ stretching of free $\beta$-diketone. This indicates that the complex did not decompose during polymerization. Elemental analysis of the product was in good agreement with the calculated value (see EXPERIMENTAL). A soluble poly(azomethine) having $\beta$ diketonate copper(II) complex in the main chain was thus obtained.

Thermogravimetric analysis (TGA) for $\mathbf{5 b}-\mathbf{C u}$ shows $5 \%$ weight loss at $250^{\circ} \mathrm{C}$ under nitrogen (Figure $1 \mathrm{~A}$ ). Subsequently, rapid weight loss was completed at $500^{\circ} \mathrm{C}$. A model complex (6) quantitatively obtained by the treatment of $\mathbf{2 a - C u}$ with benzaldehyde (Scheme 3), was used as a model compound for the repeating unit of $\mathbf{5 b}$ Cu. The TG curve for 6 shows almost same profile of that of $\mathbf{5 b}-\mathbf{C u}$ (Figure 1B). The rapid weight loss of the diamine monomer $\mathbf{2 b}-\mathbf{C u}$ was also observed at $250^{\circ} \mathrm{C}$. All $\beta$-diketonate complexes thus decompose at $250^{\circ} \mathrm{C}$ re- gardless of structure. Wholly aromatic poly(azomethine)s showed relatively high thermal stability with 5\% weight loss of the polymers observed at $360-390^{\circ} \mathrm{C}$ under nitrogen. ${ }^{21}$ TG curve $\mathbf{5 b}$-Cu under air showed rapid weight loss started at $270^{\circ} \mathrm{C}$ and completed at $400^{\circ} \mathrm{C}$. Final weight remaining was $17 \%$ corresponding to the copper oxide. The differential scanning calorimetry (DSC) thermogram of the polymer showed no melting point below $200^{\circ} \mathrm{C}$.

Table I summarizes the results of the polycondensation of $\mathbf{2 b - C u}$ with $\mathbf{3}$ under various conditions. Polymerization in nonpolar solvents such as $\mathrm{CHCl}_{3}$ and toluene with $\mathrm{LiCl}$ or molecular sieves as dehydrating agents gave only monomeric products. Polymerization of $\mathbf{2 a - C u}$ with the flexible dialdehyde (4) was performed in DMSO at room temperature with $\mathrm{H}_{2} \mathrm{SO}_{4}$. An oligomeric product was not obtained even after 1 week reaction. This can be explained by the fact that less electrophilicity of the aldehyde group of 4 compared with that of $\mathbf{3}$ due to the electron-donating alkoxy group attached at para position of the benzylaldehyde moiety. The polymerization of $\mathbf{2 a -}$ $\mathrm{Cu}$ with 4 in toluene under reflux gave a low molecular weight product in $65 \%$ yield. When $\mathbf{2 b - N i}$ was used as monomer, the product was precipitated during polymerization. The obtained product was insoluble in common organic solvents.

\section{Optical and Electronic Analysis}

Figure 2 shows the UV-Vis absorption spectra of 5b$\mathbf{C u}, \mathbf{2 b}-\mathbf{C u}$, and 6 . The peak due to the $\pi-\pi^{*}$ transition of $\mathbf{6}$ and $\mathbf{5 b}-\mathbf{C u}$ were observed at 351 , and $358 \mathrm{~nm}$, respectively. ${ }^{22}$ The slightly bathochromic shift of $\mathbf{5 b}-\mathbf{C u}$ suggests that the metal centers may be considered almost independent.

To elucidate the redox properties of the polymer, cyclic voltammetry measurements were carried out. The electrochemical behavior of bis( $\beta$-diketonato) copper(II) chelates has been well studied. ${ }^{23}$ The reduction potential of metal ions is sensitive to substituent groups in 1- and 3-positions of the $\beta$-diketonato ligands. ${ }^{24}$ The complex $\mathbf{5 b}$-Cu gave a single-broad reduction peak at $-1.77 \mathrm{~V}$ vs. $\mathrm{Ag} / \mathrm{Ag}^{+}$. The corresponding reduction of the model compound 6 was found to occur at $E_{\mathrm{pc}}=-1.64 \mathrm{~V}$. Although the reduction peak was located at slightly higher potential compared with that of the model compound, the electrochemical data as well as the absorption spectra showed that the metal centers of the multinuclear complexes may be considered nearly independent. This finding has also been reported for other coordination polymers. $^{25}$ 

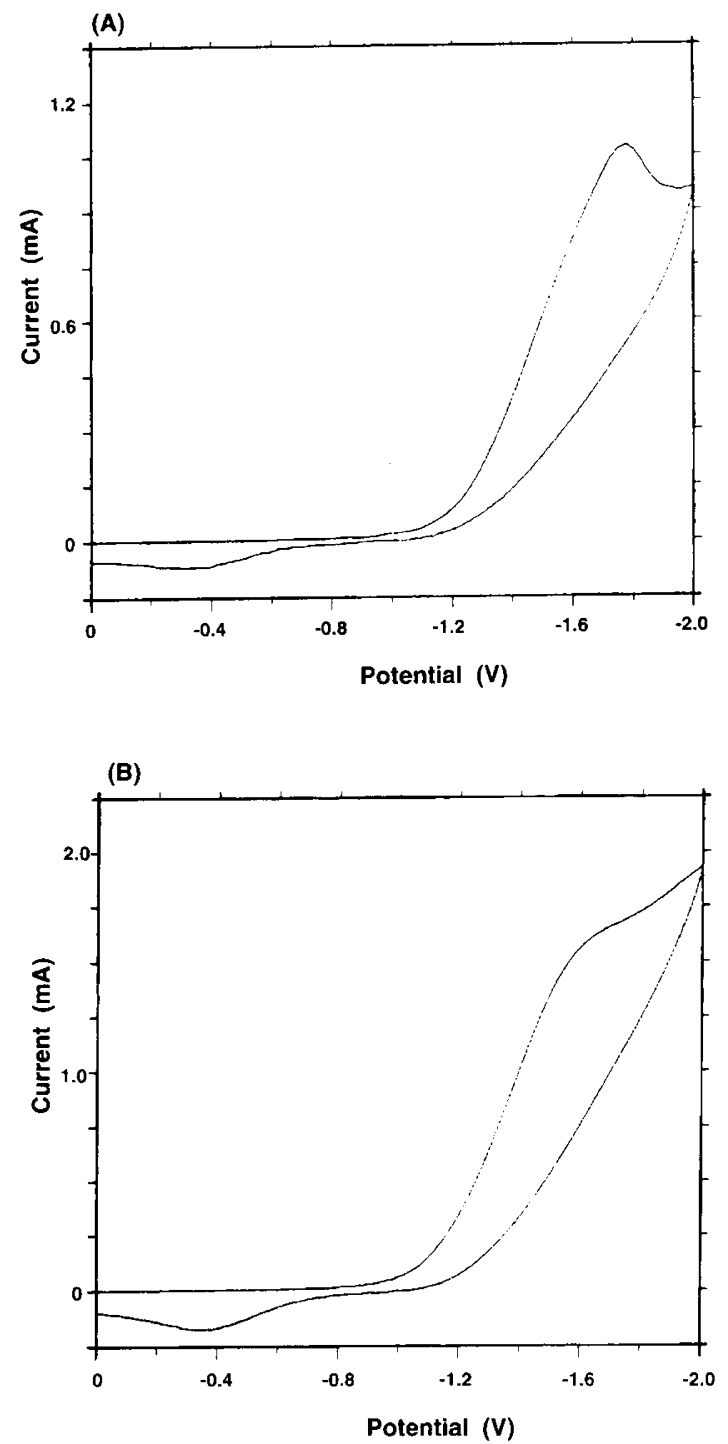

Figure 3. Cyclic voltammograms of $5 \mathbf{b}-\mathrm{Cu}(\mathrm{A})$ and 6 (B). Measured in $\mathrm{CH}_{3} \mathrm{CN}$ solution of $0.1 \mathrm{M}\left[\mathrm{NEt}_{4}\right] \mathrm{BF}_{4}$ at $100 \mathrm{mV} \mathrm{s}^{-1}$.

\section{REFERENCES}

1. P. W. Wojtkowski, Macromolecules, 20, 740 (1987).

2. P. W. Morgan, S. L. Kwolek, and T. C. Pletcher, Macromolecules, 20, 729 (1987).

3. K. Naka, A. Azuma, and Y. Chujo, Macromol. Rapid Commun., 19, 523 (1998).

4. W. Li and M. Wan, J. Appl. Polym. Sci., 62, 941 (1996).

5. S.-B. Park, H. Kim, W.-C. Z., and J. C. Jung, Macromolecules, 26, 1627 (1993).

6. H. Kim and W.-C. Zin, Polym. Bull., 39, 701 (1997).

7. O. Thomas, O. Inganäs, and M. R. Andersson, Macromolecules, 31, 2676 (1998).

8. K.-S. Lee and J. C. Won, Makromol. Chem., 190, 1547 (1989).

9. S. C. Rasmussen, D. W. Thompson, V. Singh, and J. D. Petersen, Inorg. Chem., 35, 3449 (1996).

10. I. Manners, Angew. Chem. Int. Ed. Engl., 35, 1602 (1996).

11. M. Rehahn, Acta Polym., 49, 201 (1998).

12. R. D. Archer, A. Lauterbach, and V. O. Ochaya, Polyhedron, 13, 2043 (1994).

13. H. S. Munro, P. Finocchiaro, A. Mamo, and A. Recca, Polym. Commun., 27, 202 (1986).

14. K. Hanabusa, T. Isogai, T. Koyama, and H. Shirai, Makromol. Chem., 194, 197 (1993).

15. R. D. G. Jones and L. F. Power, Aust. J. Chem., 24, 735 (1971).

16. M.E. B. Jones, M. F. Lynch, D. A. Thornton, and R. F. Webb, Makromol. Chem., 50, 232 (1961).

17. J. F. Wolfe, C. J. Eby, and C. R. Hauser, J. Org. Chem., 30, 55 (1965).

18. H. Imai, T. Shiraiwa, and M. Oiwa, Nippon Kagaku Kaishi, 1081 (1977).

19. H. Imai and T. Shiraiwa, Nippon Kagaku Kaishi, 208 (1979).

20. F. D. Lewis, A. M. Miller, and G. D. Salvi, Inorg. Chem., 34, 3173 (1995).

21. K.-S. Lee, J. C. Won, and J. C. Jung, Makromol. Chem., 190, 1547 (1989).

22. F. D. Lewis, A. M. Miller, and G. D. Salvi, Inorg. Chem., 34, 3173 (1995).

23. C. Tsiamis, P. D. Jannakoudark, N. Sachsinger, and H. Hennig, Electrochimica Acta, 38, 2623 (1993).

24. D. E. Fenton and R. L. Lintvedt, Inorg. Chem., 100, 6367 (1978).

25. R. Knapp, A. Schott, and M. Rehahn, Macromolecules, 29, 478 (1996). 